\title{
Improving decision-making agreement in child protection cases by using information regarding parents' response to an intervention: A vignette study
}

\author{
Sabine van der Asdonk ${ }^{\mathrm{a}}$, Sheila R. van Berkel ${ }^{\mathrm{a}}$, Whitney D. de Haan ${ }^{\mathrm{a}, \mathrm{b}}$, \\ Marinus H. van IJzendoorn ${ }^{\text {c,d }}$, Carlo Schuengel ${ }^{\mathrm{e}}$, Lenneke R.A. Alink ${ }^{\mathrm{a} \text {,* }}$ \\ ${ }^{a}$ Forensic Family and Youth Care Studies, Leiden University, P.O. Box 9555, 2300 RB Leiden, the Netherlands \\ ${ }^{\mathrm{b}}$ Private Law, Vrije Universiteit, De Boelelaan 1105, 1081 HV Amsterdam, the Netherlands \\ ${ }^{\mathrm{c}}$ Department of Psychology, Education and Child Studies, Erasmus University Rotterdam, P.O. Box 1738, 3000 DR Rotterdam, the Netherlands \\ ${ }^{\mathrm{d}}$ Primary Care Unit, School of Clinical Medicine, University of Cambridge, Box 113, Cambridge Biomedical Campus, Cambridge, United Kingdom \\ ${ }^{\mathrm{e}}$ Clinical Child and Family Studies, Vrije Universiteit, Van der Boechorststraat 1, 1081 BT Amsterdam, the Netherlands
}

A R T I C L E I N F O

\section{Keywords:}

Decision making

CPS

Maltreatment

Attachment

Parental sensitivity

\begin{abstract}
A B S T R A C T
Out-of-home placement decisions are complex and have a high impact on the lives of children and their parents. This study investigated whether information regarding parents' response to an attachment-based intervention impacted placement decisions and agreement among decision-makers. We presented 144 professionals and Master students with vignettes reflecting child protection cases. In addition to the standard information, half of these vignettes included a description of parents' response to an attachment-based intervention. Participants were asked to read four vignettes (randomly selected out of sixteen) and to indicate whether they would advise an out-of-home placement. Generalized Estimating Equations showed that overall, participants did not converge more in their decisions for vignettes that included a description of parents' response to an attachment-based intervention than for vignettes that contained only standard information. However, the description did increase agreement when the vignettes reflected more ambiguous cases or when parents' described response was positive. Negative descriptions of parents' response increased agreement for Master students, but not for professionals. These findings provide initial evidence that information regarding parents' response to an attachment-based intervention may enhance the quality of placement decisions.
\end{abstract}

\section{Introduction}

In child protection cases, deciding whether or not a child should be placed out of the home is one of the toughest decisions for professionals, because of its far-reaching consequences for the lives of children as well as their parents. The complexity of these decisions is reflected in low agreement among professionals (e.g., Bartelink, van Yperen, Berge, de Kwaadsteniet, \& Witteman, 2014; Britner \& Mossler, 2002) and associations with personal biases (Benbenishty et al., 2015; Munro, 1999). Another problem is that currently no evidence-based procedures are available that can be used in diagnostic evaluations potentially involving out-of-home placement. Given the high impact of out-of-home placement decisions, it is important that efforts are made to address these limitations. One aspect that might increase the quality of decisions is a more structured assessment of parents' ability to improve their parenting capacities (e.g., Budd, 2001, 2005; Harnett,
2007). In the current vignette study, we investigated whether decisionmaking agreement regarding out-of-home placements can be improved by extending child protection reports with information regarding parents' response to an attachment-based intervention, and explored how this information was used.

When the development of a child is severely threatened by adverse circumstances such as child abuse and neglect, the ultimate step for child protection services is to place the child out of home. The devastating consequences of child abuse and neglect for children's development in various domains have been widely documented (e.g., Gilbert et al., 2009). However, placing a child out of home severely impacts children and parents, as it disrupts the attachment-relationship between children and parents (Juffer, 2010) and thwarts parents' desire to take care of their own child. Given that so much is at stake, professionals have to make placement decisions very carefully. Unfortunately, deciding on out-of-home placements is complicated by the fact that many

\footnotetext{
* Corresponding author at: Forensic Family and Youth Care Studies, P.O. Box 9555, 2300 RB Leiden, the Netherlands.

E-mail addresses: s.van.der.asdonk@fsw.leidenuniv.nl (S. van der Asdonk), berkelsvan@fsw.leidenuniv.nl (S.R.van Berkel), w.d.de.haan@vu.nl (W.D.de Haan), vanijzendoorn@essb.eur.nl (M.H. van IJzendoorn), c.schuengel@vu.nl (C. Schuengel), alinklra@fsw.leidenuniv.nl (L.R.A. Alink).
} 
different factors are involved, available information might be incomplete and contradictory, and guidelines do not always provide clear directions (Munro, 1999, 2008). Several methods have been developed and investigated to improve the decision-making process, such as risk assessment instruments and structured decision-making methods (see e.g. Bartelink, de Kwaadsteniet, ten Berge, \& Witteman, 2017; Bartelink, van Yperen, \& ten Berge, 2015). Although these methods might facilitate more transparent and structured decision-making, empirical studies regarding the reliability of these methods remain scarce and thus far have not shown substantial improvements in decisionmaking agreement among professionals (Bartelink et al., 2015). This emphasizes the difficulty of placement decisions. One reason why disagreement occurs might be because decision-makers lack enough evidence about future risk of harm. Inserting more evidence into the decision-making process should lead to increased agreement, which is one necessary component for improved decisions.

Parenting (in-)capacity is a core aspect to be considered in the context of placement decisions (Budd, 2001; Platt \& Riches, 2016). To make a well-informed statement about an out-of-home placement, professionals need to make an assessment of the parent's ability to take care of the child (Azar, Benjet, Fuhrmann, \& Cavallero, 1995; Budd, 2001). In the past few decades, several guidelines have been introduced for the assessment of parenting capacity (American Psychological Association, 1998; Azar, Lauretti, \& Loding, 1998; Budd, 2001). However, empirical studies of the effectiveness of these assessments are lacking, and the existing literature reports several limitations of their use in practice (Budd, 2001). These limitations include that evaluations reflect only a single time point, assess parents outside their daily environment, and focus more on the weaknesses than on the strengths of parents (Budd, Poindexter, Felix, \& Naik-Polan, 2001). Moreover, direct observations of parent-child interactions and an evaluation of the parent-child relationship are often lacking. Recently it has been argued that to provide a more representative and relevant assessment of parenting capacities, a structured evaluation of parents' capacity to improve relevant parenting behavior should be conducted (Cyr et al., 2012; Harnett, 2007; Lindauer, Bakermans-Kranenburg, Van IJzendoorn, \& Schuengel, 2010). As proposed, such an assessment should be based on an evidence-based intervention conducted over a brief period of a few months and should at least include systematic observations of parent-child interactions. Subsequently, this assessment of parents' response to a relevant intervention should be used as an additional source of information to support placement decisions. It is argued that such an approach could be particularly valuable for those cases that are equivocal and where an initial risk assessment does not lead to clarity regarding a possible placement decision (e.g., there is no immediate threat to the child's safety which would require acute child placement) (Harnett, 2007).

An important question in assessment is how parenting competence should be operationalized. Although there is no clear consensus on the definition (Choate \& Engstrom, 2014), parental sensitivity seems to be one of the core constructs in this context (Cyr et al., 2012; Cyr \& Alink, 2017). Parental sensitivity refers to the parent's ability to adequately perceive, interpret, and respond appropriately and in a timely fashion to signals of the child (Ainsworth, Bell, \& Stayton, 1971) and has been linked to a range of positive child outcomes, such as social functioning (e.g., Van Zeijl et al., 2006), self-regulation (Eisenberg et al., 2001), and cognitive skills (e.g., Bernier, Carlson, \& Whipple, 2010). One of the possible mechanisms through which these positive effects occur is the attachment-relationship: A sensitive parent can serve as a secure base for the child and thereby stimulate the development of a secure attachment-relationship (Ainsworth, Blehar, Waters, \& Wall, 1978; Bowlby, 1982; Juffer, Bakermans-Kranenburg, \& Van IJzendoorn, 2016). Meta-analytic evidence is consistent with sensitivity as one of the causes of secure attachment (Bakermans-Kranenburg, van IJzendoorn, \& Juffer, 2003). The attachment-relationship between parents and children has been identified as relevant for parenting capacity assessments in child protection cases (Azar et al., 1998; Budd \& Holdsworth, 1996; Cyr et al., 2012; Cyr \& Alink, 2017; Schmidt, Cuttress, Lang, Lewandowski, \& Rawana, 2007). As has been argued, children's attachment to their parents is a key element in the process of child maltreatment: As an example of the most extreme insensitive parenting, maltreatment negatively affects the attachment-relationship, which therefore cannot function as a buffer to protect children from the prolonged stress they experience due to the maltreatment and other stressful events (Cyr \& Alink, 2017). Consequently, maltreated children are likely to develop a disturbed stress regulation with negative longterm consequences for their development. A recent study showed that an attachment-based intervention that is aimed at improving parental sensitivity can lead to positive outcomes for children in maltreating families: children showed improved attachment patterns and reduced behavioral problems (Moss et al., 2011). These results underscore the relevance of parental sensitivity as a parenting skill to be addressed in the case of child maltreatment.

Following this line of reasoning, the assessment of parents' capacity to change in terms of sensitivity may help increase the quality of placement decisions by providing information with straightforward relevance for the security and developmental outcomes of children. As stated before, this capacity to change should be assessed using an evidence-based intervention (Cyr et al., 2012; Cyr \& Alink, 2017; Harnett, 2007). A good candidate intervention for such an assessment would be the Video-Feedback Intervention to promote Positive Parenting (VIPP), which is a short-term, attachment-based video-feedback intervention that focuses on improving parental sensitivity (Juffer, BakermansKranenburg, \& Van IJzendoorn, 2008). An evaluation of parenting capacities based on VIPP could overcome some of the current decisionmaking limitations (Budd, 2001) in the following ways. First, the parent-child relationship can be evaluated over time and based on direct observations, because VIPP consists of six sessions over a period of three months, in which the parent and child are videotaped during common, daily interactions. Moreover, VIPP focuses on positive interactions, so that parents' strengths are highlighted and can be observed. VIPP is effective in improving parental sensitivity (Juffer, BakermansKranenburg, \& Van IJzendoorn, 2017), also in samples at risk for child maltreatment (Negrao, Pereira, Soares, \& Mesman, 2014). Similar interventions (i.e., that are short-term and attachment-based, and include video-feedback) were shown to increase parental sensitivity in maltreating samples as well (Bernard et al., 2012; Moss et al., 2011). When parents' progress in terms of sensitivity is evaluated based on VIPP or a similar intervention, this information can be interpreted with regard to the question how likely it is that home-based support will improve parenting and thereby reduces the risk of (re)occurrences of child maltreatment (Cyr \& Alink, 2017). Providing such highly relevant, concrete, and objective information might create a more transparent decision-making process with a potentially more accurate predictive picture about adequate parenting. This may lead to a better-informed decision that leaves less room for idiosyncratic factors as well as taking guesses. The impact of such information would be, in the first round, more decision-making agreement among professionals, and in the second round, a more valid decision about the future of this child and his or her family.

In addition to the previously mentioned limitations of decisionmaking in child protection cases, several studies have indicated differences in decision-making between different groups of professionals (Britner \& Mossler, 2002; Fleming, Biggart, \& Beckett, 2015; Summers, Gatowski, \& Dobbin, 2012). For example, a previous study revealed differences between social workers and judges with respect to the information they used to determine whether an out-of-home placement would be necessary: Social workers focused more on the severity of the abuse and the outcome of previous care than judges, who focused more on the likelihood that child maltreatment would reoccur and whether the child would be able to recount being abused (Britner \& Mossler, 2002). Another study indicated that risk assessments about child 
maltreatment differed between experienced professionals and students, with students estimating higher risks than professionals (Fleming et al., 2015). However, not all studies report differences between students and experienced professionals. For instance, a recent vignette study found that both students and experienced professionals made similar child protection decisions, but differed from starting professionals (Devaney, Hayes, \& Spratt, 2017). Altogether, these findings suggest that professionals who play different roles in child protection cases (e.g., children's court judges versus social workers), or have different levels of experience, might differ in their decision-making process and specifically in their use of information about parents' reponse to the intervention.

\section{The present study}

This study was a first effort to investigate whether information about parents' response to an attachment-based intervention impacts decision-making agreement in child protection cases. We investigated this by stimulating decision-making about vignettes that consisted of case descriptions based on existing child protection reports. These reports reflected diagnostic evaluations of parenting capacity in child protection cases that are usually the basis for determining whether an out-of-home placement would be necessary in the Netherlands. We supplemented the reports with a short paragraph in which parents' response to an attachment-based video-feedback intervention similar to VIPP was described. We considered decision-making agreement as an indicator of the quality of decisions in this study, because only reliable decisions can be valid. Our main hypothesis was that participants agreed more often on placement decisions for vignettes that included such a description than for vignettes that contained only standard information. Moreover, to investigate whether results were similar for vignettes that included a positive description of parents' response and those that included a negative description, we explored differences in decision-making agreement between these two types of vignettes and vignettes that contained only standard information. Finally, we tested whether effects differed depending on participants' background (social work or child law) or their level of experience.

\section{Method}

\subsection{Sample}

The sample of this study consisted of different groups of professionals and Master students who are or will be involved in the Dutch child protection system. When there are concerns about child maltreatment in the Netherlands, the Child Protection Board (CPB) can be asked to conduct an investigation that results in an advice for the children's court judge (e.g., whether child placement would be required or an intervention should be conducted). When a child is put under supervision, a social worker from Child Protection Services (CPS) is involved as family guardian. This social worker will monitor the family throughout the supervision order and can request the children's court judge to revise the decision if necessary (e.g., to end the supervision order or to place the child out of home). These requests are investigated by the CPB as well. We included a total of 144 participants in this study: 34 social workers (including both professionals from the CPB and social workers in CPS), 25 children's court judges, 42 Master students in Education and Child Studies, and 43 Master students in Child Law. The mean age of the students was 26.45 years $(S D=6.21$; range 21-49 years), and the majority of the students were female (93.9\%). For social workers, the mean age was 41.37 years $(S D=11.47$; range 24-64 years), and again the majority were female (85.0\%). Social workers had on average 14.18 years of work experience in youth care $(S D=10.67)$, with a range from 0 to 45 years. Children's court judges were on average 52.63 years old ( $S D=7.17$ years; range $37-64$ years) and $92.0 \%$ were female. They had worked with child protection cases for 6.14 years on average $(S D=3.47$ ), ranging from 1 to 12 years.
Professionals from the CPB were recruited after obtaining approval from the National Board of Child Protection. The supervisors of six of the ten Dutch CPB offices agreed to be contacted regarding the study. The remaining four offices were already involved in a different study and therefore did not have the time to participate in the current study. Of the six supervisors who were contacted, five agreed to send out an email to their employees with information regarding the study and contact information. Social workers in CPS in the area of Utrecht (the Netherlands) were contacted by sending them an e-mail through their supervisors. Children's court judges were recruited after obtaining approval from the National Board of Justice. An information email was sent through the National Board of Family and Child Law, of which all Dutch children's court judges are members $(N=164$ at the time of recruitment). Professionals who were interested in participating could contact the researchers. Finally, Master students in Education and Child Studies and in Child Law were recruited during classes at two Dutch universities. After a short presentation about the study by one of the researchers, students who were interested could write down their email address for the researchers, so that they could be contacted.

\subsection{Procedures}

Ethical approval for this study was obtained by the ethical committee of the Institute of Education and Child Studies at Leiden University and the ethics committee for legal and criminological research at Vrije Universiteit Amsterdam. All participants signed informed consent before participating. Appointments for the study took on average $3 \mathrm{~h}$, during which the participants were presented with four vignettes. After reading a vignette and optionally making notes, participants were asked to think out loud while reasoning about the case. Next, they were asked to fill out some questionnaires about the vignette. For the professionals, the appointments took place at their office or at their home, depending on their preference, and for Master students, all appointments took place at the universities. After the appointment, Master students received a gift card and professionals received a small gift.

\subsection{Instruments}

\subsubsection{Vignettes}

The vignettes used in this study reflected assessments of parenting capacity in Dutch child protection cases. Sixteen unique vignettes were composed based on eight existing cases of the $\mathrm{CPB}$, which were edited so that they were unidentifiable and contained no more than four pages. The vignettes reflected cases of children aged between 1 and 6 years. After some background information, the vignettes provided information regarding the child's development, the parenting context, social support, and previous interventions (e.g., parents' response to sessions with a psychiatrist focusing on parental psychopathology or alcohol use or a general parenting intervention not focused on sensitive parent-child interactions). Based on these eight vignettes, a second version was created by adding a paragraph that contained a self-constructed description of the parents' response to an attachment-based video-feedback intervention (see Appendix A for an example). For four of these vignettes, this description reflected positive effects of the intervention, whereas for the remaining four vignettes the description implicated that the parent did not show significant progress following the intervention. The descriptions were added randomly to the eight vignettes, regardless of whether they were positive or negative. Each participant was randomly presented with four vignettes, including two experimental vignettes with and two control vignettes without the description regarding parents' response to the intervention. The order in which the vignettes were presented was counterbalanced (see Appendix B for an overview of the design). 


\subsubsection{Background questionnaire}

A short questionnaire was used to ask about the participants' gender, age, and education. The professionals were additionally asked about their occupation and the number of years they were working at their current jobs.

\subsubsection{Think-aloud procedure}

To obtain insight in how participants used the information about parents' response to the intervention, we used a think-aloud procedure. After the participants finished reading each vignette, they were instructed to think out loud about the vignette while discussing anything that came to mind regarding the placement of the child. If a participant remained silent for more than $30 \mathrm{~s}$, the researcher used primes to encourage the participant to keep talking about the vignette, for example "What are you thinking about right now?" (see e.g., Bus \& Kruizenga, 1989). In order to practice prior to the first think-aloud procedure, the participants were asked to think out loud while solving a calculation and by counting the number of windows in their home from their memory (Ericsson \& Simon, 1993). All think-aloud procedures were recorded; recordings for one vignette ranged from $30 \mathrm{~s}$ to $45 \mathrm{~min}$. All recordings were transcribed and double-checked by research assistants.

\subsubsection{Vignette questionnaire}

For each vignette, participants were asked to indicate what their advice or decision would be, based on information given: (a) case can be closed, no further professional involvement necessary, (b) supervision order, but the child can live with parent(s), (c) supervision order and out-of-home placement in family network (e.g., child can live with grandparent(s)), (d) supervision order and out-of-home placement in foster family, (e) supervision order and out-of-home placement in residential youth care, or (f) other. Consistent with the Dutch practice, social workers and students in Education and Child Studies were asked to give their advice about the case, whereas children's court judges and students in Child Law were asked to make a decision. As the main interest of this study was the degree to which participants agreed on whether or not to place a child out of home, the items were dichotomized into no out-of-home placement (options a and b) versus out-ofhome placement (options c, d, and e) for the analyses. Options a and b were combined as the vignettes that were used in this study were of such severity that only eight participants indicated option a (case can be closed) in their response. In case the participants indicated option $\mathrm{f}$, it was decided based on the content of their response whether their advice or decision should be treated as "no out-of-home placement", "out-of-home placement", or as missing.

\subsubsection{Use of information regarding parents' response to the intervention}

To obtain more insight in how participants used the information regarding parents' response to the attachment-based intervention while judging the vignettes, a six-point rating scale was developed. This scale ranged from (1) the participant did not mention parents' response at all, to (6) the description about parents' response was completely decisive for the advice or decision of the participant. Higher scores thus indicated that the participant paid more attention to the description of parents' response to the intervention. Six coders were trained and independently coded all transcribed think-aloud recordings of the experimental vignettes. Ambiguous transcripts were discussed during supervision meetings and the inter-rater agreement was checked by independent double-coding of two transcripts after every ten transcripts. Intraclass correlations between pairs $(I C C[1,1])$ for all doublecoded transcripts $(n=45)$ were good to excellent (range $=0.73-0.91)$.

\subsection{Statistical analyses}

Decision-making agreement was computed by first determining the percentage of participants who advised an out-of-home placement and the percentage of participants who advised against an out-of-home placement for each individual vignette. Subsequently, each participant received a score reflecting whether the participant agreed with the decision of the majority of the participants (1) or not (0). Because each participant evaluated two experimental vignettes and two control vignettes, this resulted in four scores for each participant; two reflecting decision-making agreement on experimental vignettes and two reflecting decision-making agreement on control vignettes. Finally, for each participant two decision-making agreement scores were computed for the two types of vignettes, which could range from $0=$ no agreement with the majority on either vignette, $1=$ agreement on one of the two vignettes, to $2=$ agreement on both vignettes. For interpretation purposes we converted all reported decision-making agreement scores into percentages.

As the decision-making agreement scores were non-normally distributed and equal variances could not be assumed, Generalized Estimating Equations (GEEs) were performed to investigate the differences in decision-making agreement between experimental and control vignettes and to test for possible moderation effects of professional experience, professional background, and the use of the information regarding parents' response to the intervention. GEE is an extended form of the Generalized Linear Model in SPSS that can handle repeated measurements with non-normal data. In the reported analyses, decision-making agreement was modeled as a continuous variable and an unstructured correlation matrix was specified. In the GEEs we tested for the main effect of type of vignette (experimental versus control vignettes), controlled for the main effects of professional experience (students versus professionals), professional background (social work versus law), and the use of the information regarding parents' response to the intervention. Moreover, we tested all two-way interactions with type of vignette. Because of the sequential nature of our analyses, we used the Type I sum of squares approach to test for significance (see e.g. Stupica, Sherman, \& Cassidy, 2011). Significant interactions were further investigated by comparing estimated marginal means pairwise using the least significant difference method. For the experimental vignettes, half of the vignettes included a positive description indicating that the parent improved, and the other half included a negative description indicating that the parent did not show significant progress. Therefore, two separate models for positive and negative experimental vignettes were additionally tested: one comparing the positive experimental vignettes to control vignettes and the other model comparing the negative experimental vignettes to control vignettes. As the experimental vignettes were distributed randomly across participants, regardless of whether they reflected a positive or negative evaluation, not all participants received both a positive and negative experimental vignette. Therefore the sample sizes were slightly smaller than the complete sample $(n=120$ for analyses comparing positive experimental vignettes to control vignettes and $n=108$ for analyses comparing negative experimental vignettes to control vignettes) in these analyses. Finally, we conducted post-hoc analyses to explore if only vignettes that appeared ambiguous in the control condition (i.e., percentage agreement around 50\%) increased the decision-making agreement with the experimental vignettes, a similar model was tested containing decision-making agreement scores for ambiguous control vignettes and matched experimental vignettes $(n=136$; participants were included if they had read at least one ambiguous control or one matched experimental vignette. Similar results were found when only participants who had read both an ambiguous control and a matched experimental vignette were included $[n=51]$ ).

\section{Results}

\subsection{Descriptive statistics}

For the experimental vignettes, $45 \%$ of the participants advised an out-of-home placement for one of the two cases and 10\% advised an out-of-home placement for both cases. These percentages were 
respectively $53 \%$ and $14 \%$ for the control vignettes. Participants thus advised an out-of-home placement more often for control vignettes than for experimental vignettes $(t(143)=2.05, p=.042, d=0.24)$. Professionals $(M=1.20, S D=0.93)$ advised an out-of-home placement less often than students $\operatorname{did}(M=1.57, S D=0.90, t(142)=2.31$, $p=.022, d=0.40$ ). No difference was found between participants with a background in social work $(M=1.43, S D=0.97)$ and in child law $(M=1.47, \quad S D=0.87 ; \quad t(142)=-0.23, \quad p=.814, \quad d=0.04)$. Agreement percentages for the individual vignettes ranged from 50 to $81 \%$ for control vignettes and from 52 to $88 \%$ for experimental vignettes. Decision-making agreement across all vignettes neither differed between students $(M=66.84, S D=21.47)$ and professionals $(M=73.92, S D=21.70, t(142)=-1.84, p=.068, d=0.33)$, nor between participants with a background in social work $(M=68.09$, $S D=22.21)$ or in child law $(M=70.22, S D=21.27, t(142)=-0.57$, $p=.559, d=0.10$ ).

Professionals on average paid more attention to the information about parents' response to the intervention $(M=3.25, S D=0.96)$ than students $\operatorname{did}(M=2.89, \quad S D=1.00), \quad t(142)=-2.03, \quad p=.045$, $d=0.37$. No difference was found between participants from different professional backgrounds. On average, participants paid more attention to the information about parents' response in positive experimental vignettes $(M=3.61, S D=1.53)$ than in negative experimental vignettes $(M=2.43, S D=1.22), t(83)=5.94, p<.001, d=0.85$.

\subsection{Overall difference in decision-making agreement between experimental and control vignettes}

Even though the first GEE model comparing decision-making agreement between all experimental and control vignettes revealed a significant main effect for type of vignette $(p=.045$, see Table 1),comparing the estimated marginal means revealed that the difference between control and experimental vignettes was not significant (mean difference $=0.12, p=.122, d=0.24$ ). Moreover, none of the covariates or interactions were significant, see Table 1 . This indicates that there was no overall difference in decision-making agreement between experimental and control vignettes (see Table 2 and Fig. 1).

\subsection{Difference in decision-making agreement between positive experimental and control vignettes}

The GEE model testing for differences between positive experimental and control vignettes revealed that there was a significant main effect of type of vignette, see Tables 1 and 2. This indicates that participants agreed more often on positive experimental vignettes than on control vignettes (mean difference $=0.24, p=.008, d=0.32$ ), see Fig. 1. Although professional experience was a significant covariate (mean difference $=0.30, p<.001$; professionals showed more decision-making agreement than students in general), the fact that none of the interaction terms were significant indicates that the difference in decision-making agreement between control and positive experimental vignettes was not affected by any of the covariates.

\subsection{Difference in decision-making agreement between negative experimental and control vignettes}

The GEE model comparing decision-making agreement between negative experimental and control vignettes showed that only the interaction between professional experience and type of vignette was significant, see Table 1 . Thus, no main effect for type of vignette was found (mean difference $=0.06 p=.604, d=0.19$ ). To follow up on the interaction effect, pairwise comparisons of estimated marginal means were performed. These comparisons revealed that for students, decision-making agreement was higher for negative experimental vignettes than for control vignettes (mean difference $=0.33, p=.015$, $d=0.47$ ), while for professionals there was no difference in decisionmaking agreement between the negative experimental vignettes and control vignettes (mean difference $=0.21, p=.186, d=0.31$ ), see Fig. 2 and Table 2.

\subsection{Difference in decision-making agreement between ambiguous control and matched experimental vignettes: post-hoc analysis}

Based on the percentages agreement for the different control vignettes, a selection of the most ambiguous vignettes was made that included three vignettes with an agreement percentage around 50\% (i.e. respectively 50,55 , and $55 \%$ ). The GEE model testing for differences between ambiguous control and matched experimental vignettes showed that there were main effects for type of vignette, professional experience, and the use of the description of parents' response, see Tables 1 and 2. The main effect for type of vignette indicated that participants showed higher decision-making agreement for the experimental vignettes than for ambiguous control vignettes (mean difference $=0.29, p=.026, d=0.41$ ), see Fig. 1 . Although the covariates professional experience (mean difference $=0.33, p=.013$; professionals agreed more often on their decisions than students) and the use of information regarding parents' response to the intervention

Table 1

Wald Chi-square values for all generalized estimating equations model effects predicting differences in decision-making agreement.

\begin{tabular}{|c|c|c|c|c|}
\hline \multirow[t]{3}{*}{ Intercept } & $\begin{array}{l}\text { Control versus all } \\
\text { experimental vignettes }\end{array}$ & $\begin{array}{l}\text { Positive experimental versus } \\
\text { control vignettes }\end{array}$ & $\begin{array}{l}\text { Negative experimental } \\
\text { versus control vignettes }\end{array}$ & $\begin{array}{l}\text { Ambiguous control versus } \\
\text { matched experimental vignettes }\end{array}$ \\
\hline & $(N=144)$ & $(n=120)$ & $(n=108)$ & $(n=136)$ \\
\hline & $1519.28^{* *}$ & $1148.05^{* *}$ & $720.16^{* *}$ & $396.90^{* *}$ \\
\hline Type of vignette & $4.01 *$ & $5.88^{*}$ & 1.94 & $8.46^{* *}$ \\
\hline Professional experience & 3.48 & $14.22 * *$ & 0.32 & $7.53^{* *}$ \\
\hline Professional background & 0.18 & 1.02 & 0.04 & 0.04 \\
\hline Information regarding parents' response & 1.55 & 0.58 & 0.45 & $7.34 * *$ \\
\hline Type of vignette*professional experience & 2.11 & 0.13 & $7.10^{* *}$ & 0.62 \\
\hline Type of vignette* professional background & 0.23 & 0.09 & 0.18 & 0.05 \\
\hline $\begin{array}{l}\text { Type of vignette*information regarding } \\
\text { parents' response }\end{array}$ & 2.43 & 1.49 & 0.78 & 0.58 \\
\hline
\end{tabular}

Note: $n=$ number of participants included in the analyses (total $N=144$ ). For the analysis comparing ambiguous control and matched experimental vignettes,

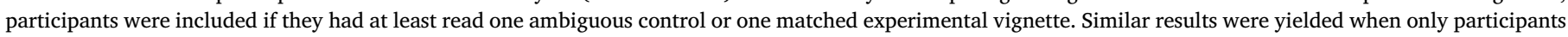
that had read both an ambiguous control and a matched experimental vignette were included $(n=51)$.

$* p<.05$.

** $p<.01$. 
Table 2

Overview descriptive statistics of GEE analyses testing for differences in decision-making agreement between experimental and control vignettes.

\begin{tabular}{|c|c|c|c|c|}
\hline & Total $(N=144)$ & $\begin{array}{l}\text { Positive experimental and control } \\
\text { vignettes }\end{array}$ & $\begin{array}{l}\text { Negative experimental and control } \\
\text { vignettes }\end{array}$ & $\begin{array}{l}\text { Ambiguous control and matched experimental } \\
\text { vignettes }\end{array}$ \\
\hline & & $(n=120)$ & $(n=108)$ & $(n=136)$ \\
\hline & $M(S D)$ & $M(S D)$ & $M(S D)$ & $M(S D)$ \\
\hline Experimental vignettes & $72.92(31.22)$ & $77.35(38.00)^{*}$ & 70.37 (43.25) & $72.34(41.88)^{* * *}$ \\
\hline Social & $73.03(32.08)$ & 75.41 (39.39) & $72.73(42.84)$ & $72.00(41.85)$ \\
\hline Law & $72.80(30.46)$ & $79.47(36.65)$ & $67.93(43.96)$ & 72.73 (42.39) \\
\hline Students & $72.45(32.21)$ & $71.88(41.22)$ & $76.39(40.22)^{* * *}$ & 68.55 (44.57) \\
\hline Professionals & $73.92(29.32)$ & $89.19(26.71)$ & $58.34(47.06)$ & $79.69(35.60)$ \\
\hline Control vignettes & $65.28(32.54)$ & $66.25(31.86)^{*}$ & $62.97(33.75)$ & $53.80(48.74)^{* * *}$ \\
\hline Social & $63.16(29.85)$ & $63.28(29.87)$ & $61.82(30.37)$ & $51.04(48.91)$ \\
\hline Law & $67.65(35.37)$ & 69.64 (33.95) & $64.15(37.18)$ & $56.82(48.93)$ \\
\hline Students & $61.23(32.53)$ & $61.73(31.89)$ & $59.03(33.91)^{* * *}$ & $46.03(48.61)$ \\
\hline Professionals & $73.92(31.16)$ & 75.64 (30.07) & $70.84(32.46)$ & 70.69 (45.35) \\
\hline
\end{tabular}

Decision-making agreement on experimental vignettes (upper part of table) was compared with decision-making agreement on control vignettes (lower part of table). Interaction effects with several subgroups of participants were tested: (1) to compare participants with a social background to participants with a law background, and (2) to compare Master students to professionals. Asterisks indicate a significant difference in decision-making agreement between experimental vignettes and the corresponding group of control vignettes.

$* p<.050$.

*** $p<.010$.

$(B=0.23, S E=0.26, p=.006$; stronger focus on parents' response was related to more decision-making agreement in general) were significant, none of the interaction terms with type of vignette were significant. This indicates that the increase in decision-making agreement for the selection of ambiguous vignettes did not depend on any of the covariates.

\section{Discussion}

This vignette study was a first effort to investigate whether the quality of placement decisions can be enhanced by extending child protection reports with a description of parents' response to an attachment-based intervention. Overall, decision-makers did not agree more often on whether or not an out-of-home placement was necessary for case reports that included a description of parents' response to the intervention than for regular case reports. However, for the cases that were most ambiguous, we found an overall increase in decision-making agreement when a description of parents' response was included. Moreover, when we looked specifically at the inclusion of a positive description of parents' response, we found increased agreement as well. Finally, case reports that included a negative description resulted in more decision-making agreement for Master students, but not for professionals. These findings provide preliminary evidence that using information regarding parents' response to an attachment-based intervention to support placement decisions in child protection cases may increase the quality of decision-making.

The finding that overall, we did not find increased agreement among decision-makers when a description regarding parents' response to an attachment-based intervention was added to the case reports is not in line with our hypothesis. However, although the goal of our study was to test the effects of adding this description to equivocal CPS cases, preliminary analyses indicated that for some of these cases, the agreement on whether or not to place the child out of home was already relatively high (around 70-80\%). Therefore, the finding that adding the description to a selection of ambiguous cases (for which the agreement was around $50 \%$ ), led to more uniform decision-making is promising. This might suggest that especially for cases that remain equivocal after an initial risk assessment, the information regarding parents' response to an attachment-based information can provide clear and relevant information that enables decision-makers to make more objective decisions. However, because we performed this analysis in an exploratory manner, further research is necessary to establish this finding more firmly.

Furthermore, we found that when the description reflected a positive response of the parent to the attachment-based intervention, all participants showed higher decision-making agreement. However,

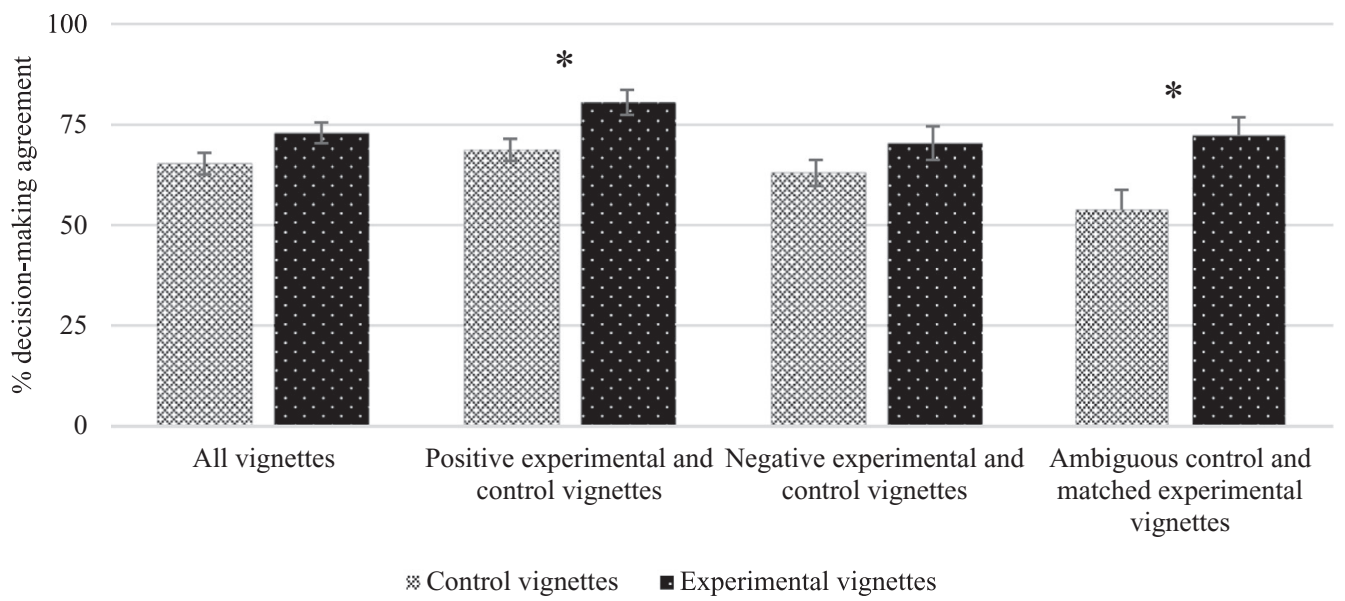

Fig. 1. Main effects for differences in decision-making agreement between experimental and control vignettes. 
100

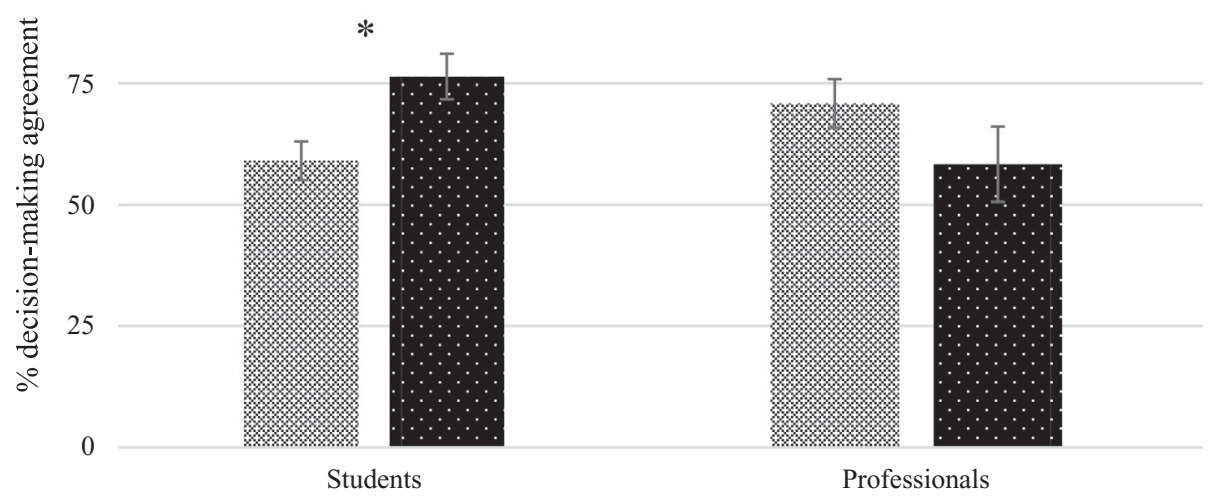

Control vignettes Experimental vignettes

Fig. 2. Interaction effect for differences in decision-making agreement between negative experimental and control vignettes for students and professionals.

when the description indicated that the parent did not show significant progress following the intervention, only Master students, and not professionals, showed more decision-making agreement. Preliminary analyses indicated that participants focused more on positive descriptions of parents' response to an intervention than on negative descriptions while they were judging the cases (large effect size), and that professionals generally focused more on the description of parents' response than students did (small effect size). However, we found that the extent to which participants focused on this information while thinking aloud did not influence any of the results. A possible explanation for the different effects of the negative description could be related to professionals' and students' perception of risks for the child. For instance, in a previous study it was found that students generally estimated higher risks in families in child protection than experienced professionals (Fleming et al., 2015). Based on these results, it could be speculated that students are more affected by negative information than professionals and that this influences their decision-making. On the other hand, experienced professionals could be more inclined, based on their experiences with individual cases, to think that if one intervention does not significantly improve parenting skills, another intervention provided under different circumstances could still be effective for these parents. This might explain why professionals were more affected by positive descriptions than by negative descriptions. In future studies, it would be interesting to further explore the different effects of positive and negative descriptions of parents' response to an intervention and to uncover factors that caused the differences between professionals and students.

Interestingly, the differences in decision-making agreement between case reports with and without a description of parents' response to the intervention were not affected by the extent to which decisionmakers focused on this information while thinking out loud. Perhaps the absence of such an effect is related to the procedure of our study. We asked participants to think out loud right after they had first read the case report. Prior to stating their advice or decision about the case, we asked the participants to fill out a risk assessment questionnaire (as would be usual in practice). It could be that their reasoning about the case was influenced by this risk assessment, and that this changed the value they attached to the description of parents' response. However, as we did not explicitly ask the decision-makers whether or not their decision about the case was influenced by this information, this issue remains unclear. On the other hand, the fact that the only difference between the two types of case reports was the description about parents' response suggests that participants were at least implicitly influenced by this information.

Based on a previous study reporting that children's court judges used different information for their placement decisions than social workers (Britner \& Mossler, 2002), we expected differences between these subgroups in our study as well. However, in none of the analyses we found differences between participants with a background in social work and a background in child law. The fact that we did not find such differences indicates that although decision-makers vary in their education and their position in the decision-making process, the information about parents' response to an attachment-based intervention has a similar effect: they converge more in their decisions. This might further underscore our assumption that providing this information to decisionmakers can lead to more objective decisions.

Altogether, the general picture that can be derived from our results is that providing decision-makers with information regarding parents' response to an attachment-based intervention can lead to more decision-making agreement and thus increase the predictability of such decisions. Even though the effect sizes were small and we did not find increased agreement in all analyses, given the high impact of placement decisions all improvements of the decision-making process could be considered as relevant. Although we did not explicitly ask the professionals and students how they used the information regarding parents' response for their decisions, the fact that decision-makers were more uniform in most of our analyses may suggest that this information can enable them to form a more objective view of the parent's abilities, and hence the child's safety, to guide their decisions. Using information regarding parents' response to an intervention to support placement decisions is a procedure that has been suggested by several researchers to increase the quality of decisions (Cyr et al., 2012; Cyr \& Alink, 2017; Harnett, 2007). Reaching more consensus on decisions is an essential step in the process of improving the quality of decision-making, because without sufficient reliability (i.e., multiple professionals agreeing on the optimal course or courses of action for the same case), decisions cannot be valid (i.e., beneficial for children's quality of life in the future, resulting in fewer new reports of child maltreatment).

The description of parents' response was based on an attachmentbased video-feedback intervention focused on the improvement of parents' sensitivity, a universal parenting skill that is essential to children's development (e.g., Ainsworth et al., 1971; Bernier et al., 2010; Eisenberg et al., 2001; Van Zeijl et al., 2006) and presumably especially relevant in families where child maltreatment occurs (Cyr et al., 2012; Cyr \& Alink, 2017). Even though the presence of risk factors, such as parents' psychological problems or substance abuse, can set severe limitations to the parents' abilities to take care of the child, when a case remains equivocal despite the presence of these risk factors, it might be especially valuable information whether actual parenting behavior that is critical to the child's development, such as parental sensitivity, can be improved by the parent (Cyr et al., 2012). The current findings are, although preliminary, in favor of this assumption. Although it might be 
argued that parents' response to a certain intervention, provided at a certain time point does not prove whether or not a parent is able to change in response to other interventions, provided at other time points, it could be reasoned that when a placement decision has to be made within a limited amount of time, a recent evaluation of the effects of an evidence-based intervention provides a valuable indication for this decision. The fact that presently only a very limited number of interventions are available that have been proven to prevent or stop child maltreatment (Euser, Alink, Stoltenborgh, BakermansKranenburg, \& Van IJzendoorn, 2015) suggests that more research in this area is highly necessary. If there is more knowledge on which types of families respond better to which types of interventions and under which circumstances, this could help to further disentangle this issue.

Our assumption that parental change in sensitivity is an important aspect to consider in decision-making is also in line with two recent meta-analyses which identified parenting interventions among the most effective interventions to reduce child maltreatment (Euser et al., 2015; Van der Put, Assink, Gubbels, \& Boekhout van Solinge, 2018). However, parents reported for maltreatment likely suffer from additional problems such as severe psychopathology, which require supplementary treatment. Ideally, given the complexity of problems encountered in maltreating families, an intervention aimed at parental sensitivity should be embedded in a PCA program that also focuses on other apparent risk factors in a family, so that parents' changes in sensitivity can be interpreted within this broader context. In addition, when such a PCA leads to a positive recommendation regarding child placement (i.e., children return to or stay at home with their parents), this should likely always be followed up with additional family support to which the parent(s) seem susceptible and to both monitor the family and continue the process of improvement.

\subsection{Limitations}

In light of the current findings, several limitations of this study should be noted. First, we used vignettes to simulate decision-making in child protection cases and supplemented the vignettes with a fictional paragraph about parents' response to an intervention. Participants were asked individually to provide their decision or advice, without the possibility of discussing the case with colleagues and consulting sources (e.g., talk to parents or involved social workers), as would be usual in practice. Therefore, our study design did not completely resemble decision-making in practice. However, the vignettes were based on existing child protection cases, and we asked a panel of professionals in child protection services for their feedback, and adapted the vignettes until they indicated that the content of the vignettes was representative for the case information they would normally receive. Another strong aspect of the use of vignettes in this study design is that it allowed us to randomly add the description of parents' response to the vignettes in counterbalanced order, so it is possible to draw causal inferences about improvements in decision-making agreement based on this information. This design was required as a first step in research before exploring the effects of using evaluations of parents' response to an intervention in clinical practice. Another limitation is related to the assessment of how participants used the information about parents' response: We did not explicitly ask participants how this information affected their decisions. Although the think out loud transcripts did give more insight in the extent to which participants focused on this information while they were judging the cases, this measure is quite implicit. In future studies, adding more explicit measures would be useful to form a clearer picture of how this information should be used by decision-makers in practice.

\section{Conclusion and implications}

In this study we showed that extending CPS case reports with a description of parents' response to an attachment-based intervention generally increased decision-making agreement and as a result, may enhance the quality of placement decisions. Since a higher quality of decisions can only be reached when there is sufficient reliability, this is a valuable finding in the process of improving decision-making. Although the results of this study are promising, clinical investigations are warranted to investigate if the validity of decisions improves as well with this approach. Accordingly, in future studies it will be important to focus on whether the use of a diagnostic instrument to evaluate parents' response to an intervention benefits children's quality of life. If for instance the response to intervention turns out in future studies to be a good predictor of the extent to which families benefit from parenting support and thus reduce the risk of recurring child maltreatment, placement decisions may be made not only with more confidence but also with better outcomes for children.

\section{Funding}

This research did not receive any specific grant from funding agencies in the public, commercial, or not-for-profit sectors.

\section{Declaration of Competing Interest}

None.

\section{Appendix A}

Example of a supplemented paragraph to one of the vignettes (translated from Dutch)

"The Child Protection Board asked the case-manager to start a video-interaction training with mother to provide a structured evaluation of mothers' parenting capacities. Mother completed 6 (intensive) sessions. The intervener notes that at the start of the training, it was difficult to motivate mother to cooperate. The main reason for this was that mother was afraid that her drug addiction would be addressed in the training. After the intervener made clear that the training would focus on parenting capacities and mothers' interactions with T., mother was prepared to cooperate. The intervener notes that mother clearly improved during the last two sessions. She approaches T. in a more positive manner and is able to set restrictions to his behavior, although she still finds it difficult to offer him an alternative or explain to him why something is not allowed. Furthermore, the intervener notes that he observed that mother now enjoys playing with T. more, and she observes and follows T. well while they are playing. This is a clear change compared to the start of the training. Mother is more positive towards T. and he receives more affection and warmth." 


\section{Appendix B}

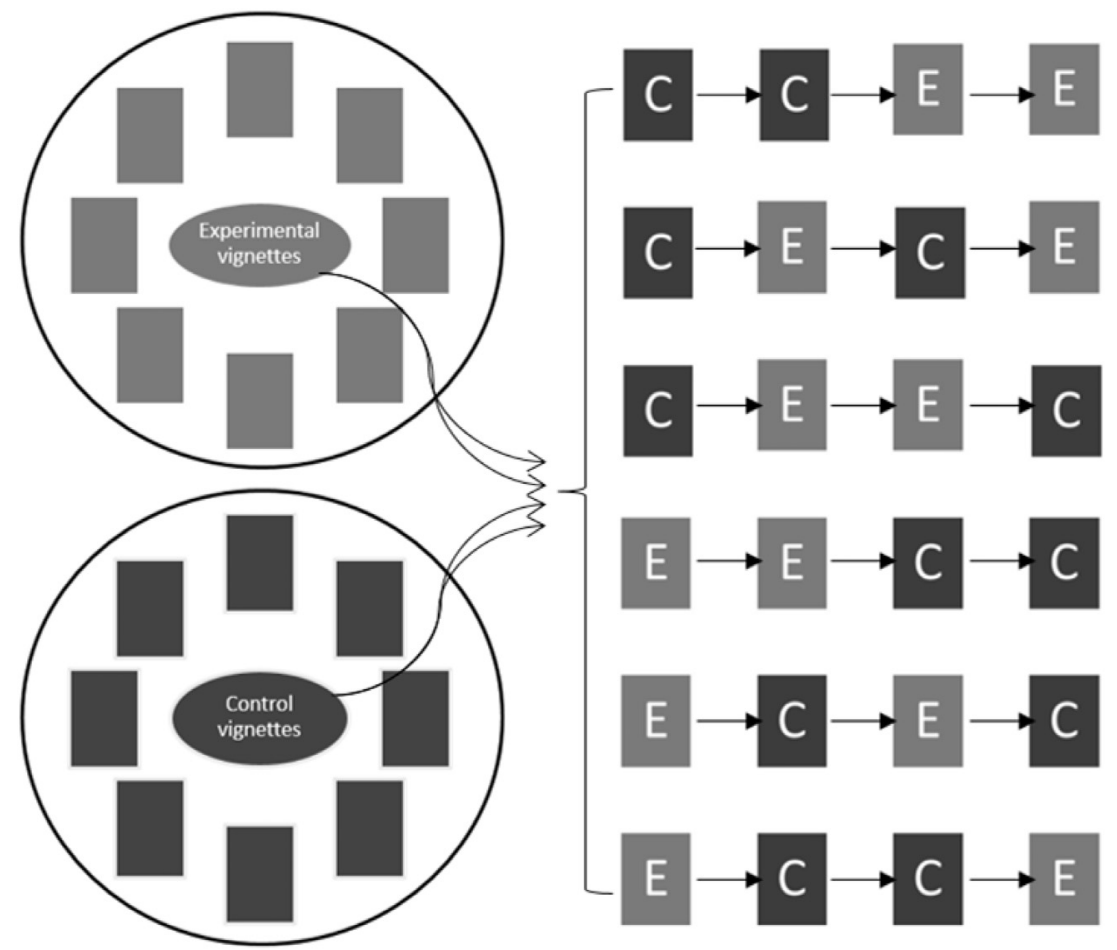

Fig. B1. Examples of random presentation of two experimental (E) and two control (C) vignettes to participants according to a counterbalanced repeated measures design

\section{References}

Ainsworth, M. D. S., Bell, S. M., \& Stayton, D. J. (1971). Individual differences in strangesituation behavior in one-year-olds. In H. R. Schaffer (Ed.). The origins of human social relations (pp. 17-57). London: Academic.

Ainsworth, M. D. S., Blehar, M. C., Waters, E., \& Wall, S. N. (1978). Patterns of attachment: A psychological study of the strange situation. Hillsdale, NJ: Lawrence Erlbaum Associates.

American Psychological Association (1998). Committee on professional practice and standards. Retrieved from http://www.apa.org/about/governance/bdcmte/ standards.aspx.

Azar, S. T., Benjet, C. L., Fuhrmann, G. S., \& Cavallero, L. (1995). Child maltreatment and termination of parental rights - Can behavioral-research help Solomon. Behavior Therapy, 26(4), 599-623. https://doi.org/10.1016/S0005-7894(05)80035-8.

Azar, S. T., Lauretti, A. F., \& Loding, B. V. (1998). The evaluation of parental fitness in termination of parental rights cases: A functional-contextual perspective. Clinical Child and Family Psychology Review, 1(2), 23.

Bakermans-Kranenburg, M. J., van IJzendoorn, M. H., \& Juffer, F. (2003). Less is more: Meta-analyses of sensitivity and attachment interventions in early childhood. Psychological Bulletin, 129(2), 195-215. https://doi.org/10.1037/0033-2909.129.2. 195.

Bartelink, C., de Kwaadsteniet, L., ten Berge, I. J., \& Witteman, C. L. M. (2017). Is it safe? Reliability and validity of structured versus unstructured child safety judgments. Child \& Youth Care Forum, 46(5), 745-768. https://doi.org/10.1007/s10566-017 9405-2.

Bartelink, C., van Yperen, T. A., Berge, I. J., de Kwaadsteniet, L., \& Witteman, C. L. M. (2014). Agreement on child maltreatment decisions: A nonrandomized study on the effects of structured decision-making. Child \& Youth Care Forum, 43(5), 639-654. https://doi.org/10.1007/s10566-014-9259-9.

Bartelink, C., van Yperen, T. A., \& ten Berge, I. J. (2015). Deciding on child maltreatment: A literature review on methods that improve decision-making. Child Abuse \& Neglect, 49, 142-153. https://doi.org/10.1016/j.chiabu.2015.07.002.

Benbenishty, R., Davidson-Arad, B., Lopez, M., Devaney, J., Spratt, T., Koopmans, C., ... Hayes, D. (2015). Decision making in child protection: An international comparative study on maltreatment substantiation, risk assessment and interventions recommendations, and the role of professionals' child welfare attitudes. Child Abuse \& Neglect, 49, 63-75. https://doi.org/10.1016/j.chiabu.2015.03.015.

Bernard, K., Dozier, M., Bick, J., Lewis-Morrarty, E., Lindhiem, O., \& Carlson, E. (2012). Enhancing attachment organization among maltreated children: Results of a randomized clinical trial. Child Development, 83(2), 623-636. https://doi.org/10.1111/j. 1467-8624.2011.01712.x.

Bernier, A., Carlson, S. M., \& Whipple, N. (2010). From external regulation to self- regulation: Early parenting precursors of young children's executive functioning. Child Development, 81(1), 326-339. https://doi.org/10.1111/j.1467-8624.2009. 01397.x.

Bowlby, J. (1982). Attachment and loss. American Journal of Orthopsychiatry, 52, 664-678.

Britner, P. A., \& Mossler, D. G. (2002). Professionals' decision-making about out-of-home placements following instances of child abuse. Child Abuse \& Neglect, 26(4), 317-332. https://doi.org/10.1016/S0145-2134(02)00311-3.

Budd, K. S. (2001). Assessing parenting competence in child protection cases: A clinical practice model. Clinical Child and Family Psychology Review, 4(1), 18.

Budd, K. S. (2005). Assessing parenting capacity in a child welfare context. Children and Youth Services Review, 27(4), 429-444. https://doi.org/10.1016/j.childyouth.2004. 11.008.

Budd, K. S., \& Holdsworth, M. J. (1996). Issues in clinical assessment of minimal parenting competence. Journal of Clinical Child Psychology, 25(1), 2-14. https://doi.org/ 10.1207/s15374424jccp2501_1.

Budd, K. S., Poindexter, L. M., Felix, E. D., \& Naik-Polan, A. T. (2001). Clinical assessment of parents in child protection cases: An empirical analysis. Law and Human Behavior, 25(1), 93-108. https://doi.org/10.1023/A:1005696026973.

Bus, A. G., \& Kruizenga, T. H. (1989). Diagnostic problem-solving behavior of expert practitioners in the field of learning-disabilities. Journal of School Psychology, 27(3), 277-287. https://doi.org/10.1016/0022-4405(89)90042-3.

Choate, P. W., \& Engstrom, S. (2014). The "good enough" parent: Implications for child protection. Child Care in Practice, 20(4), 14. https://doi.org/10.1080/13575279. 2014.915794.

Cyr, C., \& Alink, L. R. A. (2017). Child maltreatment: The central roles of parenting capacities and attachment. Current Opinion in Psychology, 15, 81-86. https://doi.org/10. 1016/j.copsyc.2017.02.002.

Cyr, C., Dubois-Comtois, K., Geneviève, M., Poulin, C., Pascuzzo, K., Losier, V., ... Moss, E. (2012). Attachment theory in the assessment and promotion of parental competency in child protection cases. In A. Muela (Ed.). Child abuse and neglect - A multidimensional approach (pp. 63-86). Croatia: InTech.

Devaney, J., Hayes, D., \& Spratt, T. (2017). The influences of training and experience in removal and reunification decisions involving children at risk of maltreatment: Detecting a 'beginner dip'. British Journal of Social Work, 47(8), 2364-2383. https:// doi.org/10.1093/bjsw/bcw175.

Eisenberg, N., Losoya, S., Fabes, R. A., Guthrie, I. K., Reiser, M., Murphy, B., ... Padgett, S. J. (2001). Parental socialization of children's dysregulated expression of emotion and externalizing problems. Journal of Family Psychology, 15(2), 183-205. https://doi. org/10.1037//0893-3200.15.2.183.

Ericsson, K. A., \& Simon, H. A. (1993). Protocol analysis: Verbal reports as data. Revised EditionCambridge, MA: A Bradford Book/The MIT Press.

Euser, S., Alink, L. R. A., Stoltenborgh, M., Bakermans-Kranenburg, M. J., \& Van 
IJzendoorn, M. H. (2015). A gloomy picture: A meta-analysis of randomized controlled trials reveals disappointing effectiveness of programs aiming at preventing child maltreatment. BMC Public Health, 15. https://doi.org/10.1186/s12889-015 2387-9.

Fleming, P., Biggart, L., \& Beckett, C. (2015). Effects of professional experience on child maltreatment risk assessments: A comparison of students and qualified social workers. British Journal of Social Work, 45(8), 2298-2316. https://doi.org/10.1093/ bjsw/bcu090.

Gilbert, R., Widom, C. S., Browne, K., Fergusson, D., Webb, E., \& Janson, S. (2009). Burden and consequences of child maltreatment in high-income countries. Lancet, 373(9657), 68-81. https://doi.org/10.1016/S0140-6736(08)61706-7.

Harnett, P. H. (2007). A procedure for assessing parents' capacity for change in child protection cases. Children and Youth Services Review, 29(9), 1179-1188. https://doi. org/10.1016/j.childyouth.2007.04.005.

Juffer, F. (2010). Beslissen over kinderen in problematische opvoedsituaties: Inzichten uit gehechtheidsonderzoek. Raad voor de Rechtspraak: Research Memoranda, 6(6).

Juffer, F., Bakermans-Kranenburg, M. J., \& Van IJzendoorn, M. H. (2016). Video-feedback intervention to promote positive parenting and sensitive discipline (VIPP-SD): Development and meta-analytical evidence of its effectiveness. In H. Steele, \& M. Steele (Eds.). Handbook of attachment-based interventions. New York: Guilford.

Juffer, F., Bakermans-Kranenburg, M. J., \& Van IJzendoorn, M. H. (2017). Pairing attachment theory and social learning theory in video-feedback intervention to promote positive parenting. Current Opinion in Psychology, 15, 189-194. https://doi.org/ 10.1016/j.copsyc.2017.03.012

Juffer, F., Bakermans-Kranenburg, M. J., \& Van IJzendoorn, M. H. E. (2008). Promoting positive parenting: An attachment-based intervention. New York: Taylor \& Francis.

Lindauer, R. J. L., Bakermans-Kranenburg, M. J., Van IJzendoorn, M. H., \& Schuengel, C. (2010). Thuiswonen of uithuisplaatsen: Betrouwbaarheid van de besluitvorming en innovatie van beslisdiagnostiek op basis van de capaciteit tot verbetering van ouderlijke pedagogische vaardigheden middels een evidence-based interventie [Out-of-home placement: Reliability of the decision process and innovation of diagnostic procedures on the basis of assessment of capacity for change in parenting through evidence-based intervention]. Unpublished research proposalAmsterdam: Bascule.

Moss, E., Dubois-Comtois, K., Cyr, C., Tarabulsy, G. M., St-Laurent, D., \& Bernier, A. (2011). Efficacy of a home-visiting intervention aimed at improving maternal sensitivity, child attachment, and behavioral outcomes for maltreated children: A randomized control trial. Development and Psychopathology, 23(1), 195-210. https:// doi.org/10.1017/S0954579410000738.

Munro, E. (1999). Common errors of reasoning in child protection work. Child Abuse \& Neglect, 23(8), 745-758. https://doi.org/10.1016/S0145-2134(99)00053-8.

Munro, E. (2008). Effective child protection. London: SAGE Publications Ltd.

Negrao, M., Pereira, M., Soares, I., \& Mesman, J. (2014). Enhancing positive parent-child interactions and family functioning in a poverty sample: A randomized control trial. Attachment \& Human Development, 16(4), 315-328. https://doi.org/10.1080/ 14616734.2014.912485.

Platt, D., \& Riches, K. (2016). Assessing parental capacity to change: The missing jigsaw piece in the assessment of a child's welfare? Children and Youth Services Review, 61, 141-148. https://doi.org/10.1016/j.childyouth.2015.12.009.

Schmidt, F., Cuttress, L. J., Lang, J., Lewandowski, M. J., \& Rawana, J. S. (2007). Assessing the parent-child relationship in parenting capacity evaluations: Clinical applications of attachment research. Family Court Review, 45(2), 247-259. https:// doi.org/10.1111/j.1744-1617.2007.00141.x.

Stupica, B., Sherman, L. J., \& Cassidy, J. (2011). Newborn irritability moderates the association between infant attachment security and toddler exploration and sociability. Child Development, 82(5), 1381-1389. https://doi.org/10.1111/j.1467-8624.2011. 01638.x.

Summers, A., Gatowski, S., \& Dobbin, S. (2012). Terminating parental rights: The relation of judicial experience and expectancy-related factors to risk perceptions in child protection cases. Psychology Crime \& Law, 18(1), 95-112. https://doi.org/10.1080/ 1068316x.2011.589388.

Van der Put, C. E., Assink, M., Gubbels, J., \& Boekhout van Solinge, N. F. (2018). Identifying effective components of child maltreatment interventions: A meta-analysis. Clinical Child and Family Psychology Review, 21(2), 171-202. https://doi.org/10. 1007/s10567-017-0250-5.

Van Zeijl, J., Mesman, J., Van Ijzendoorn, M. H., Bakermans-Kranenburg, M., Juffer, F., Stolk, M. N., ... Alink, L. R. A. (2006). Attachment-based intervention for enhancing sensitive discipline in mothers of 1- to 3-year-old children at risk for externalizing behavior problems: A randomized controlled trial. Journal of Consulting and Clinical Psychology, 74, 994-1005. https://doi.org/10.1037/0022-006X.74.6.994. 